\title{
Morphology and phylogeny of Phaeoseptum mali sp. nov. (Phaeoseptaceae, Pleosporales) on bark of Malus halliana
}

\author{
Phukhamsakda $\mathbf{C}^{1}$, Jeewon $\mathrm{R}^{2}$, McKenzie $\mathrm{EHC}^{3}, \mathrm{Xu} \mathrm{JC}^{4}$ \\ ${ }^{1}$ Center of Excellence in Fungal Research, Mae Fah Luang University, Chiang Rai 57100, Thailand \\ ${ }^{2}$ Department of Health Sciences, Faculty of Science, University of Mauritius, Reduit, Mauritius \\ ${ }^{3}$ Manaaki Whenua Landcare Research, Private Bag 92170, Auckland, New Zealand \\ ${ }^{4}$ Key Laboratory for Plant Diversity and Biogeography of East Asia, Kunming Institute of Botany, Chinese Academy of \\ Science, Kunming 650201, Yunnan, People's Republic of China
}

Phukhamsakda C, Jeewon R, McKenzie EHC, Xu JC 2019 - Morphology and phylogeny of Phaeoseptum mali sp. nov. (Phaeoseptaceae, Pleosporales) on bark of Malus halliana. Asian Journal of Mycology 2(1), 118-128, Doi 10.5943/ajom/2/1/6

\begin{abstract}
A novel species, Phaeoseptum mali is described based on its distinct morphs and phylogenetic relationships among members of Phaeoseptaceae (Pleosporales). Phaeoseptum mali can be distinguished from other species of Phaeoseptum by its ascomatal, asci and ascospore characters. A detailed illustration and a description of $P$. mali are provided. Phylogenetic analyses of a combined LSU, ITS, SSU, tef1, and rpb2 sequence dataset confirmed its placement within Phaeoseptaceae and its relationships to $P$. aquaticum and $P$. terricola.
\end{abstract}

Key words - 1 new species - China - Dicotyledon - Dothideomycetes - Fungus

\section{Introduction}

Among the Dothideomycetes (bitunicate ascomycetes), Pleosporales is one of the most diverse orders with many new species recently described incorporating DNA sequence data (Kodsueb et al. 2006, Pinnoi et al. 2007, Zhang et al. 2008, 2009, Wanasinghe et al. 2017a, b, 2018, Wijayawardene et al. 2017, 2018, Hyde et al. 2018). Molecular dating has also been used to clarify evolutionary relationships across these bitunicates (Liu et al. 2017).

The family Phaeoseptaceae was established by Hyde et al. (2018), and contains two accepted genera, Lignosphaeria and Phaeoseptum (with P. aquaticum as the generic type). Putative strains of Decaisnella formosa (BCC 25616 and BCC 25617), Neolophiostoma pigmentatum (MFLUCC 10-0129), and Thyridaria macrostomoides (GKM 1033 and GKM 1159), have also been reported to belong to this family (Ariyawansa et al. 2015, Phukhamsakda et al. 2016, Liu et al. 2017, Hyde et al. 2018). Species of Phaeoseptaceae commonly occur on decaying wood in both terrestrial and aquatic habitats. Phaeoseptum was introduced based on collections from a woody substrate submerged in a freshwater ecosystem. According to Zhang et al. (2013), the characteristics of the genus include immersed ascomata, narrowly cellular pseudoparaphyses, cylindrical to broadly clavate asci, and dictyosporous, pale brown ascospores with thickened septa.

In this study, we provide an update on the phylogeny of the Phaeoseptaceae and describe a novel species of Phaeoseptum from Malus halliana collected in China. The phylogeny is based on a multi-gene dataset. 


\section{Materials \& Methods}

\section{Sample collection, morphological study, and isolation}

Fresh specimens of the bark of Malus halliana Koehne were collected from southern part of China, in the botanical garden of Kunming Institute of Botany, Chinese Academy of Science, Kunming, Yunnan, China. The specimens were packed into paper bags and transported to the laboratory. Pure cultures were obtained from single ascospores on malt extract agar (MEA; 62 g/l) in distilled water following the method of Chomnunti et al. (2014). Cultures were incubated at 25 ${ }^{\circ} \mathrm{C}$ for one month under standard light cycles of $12 \mathrm{hrs} \mathrm{light/} 12 \mathrm{hrs}$ dark (Liu et al. 2010). The type specimen is deposited in Mae Fah Luang University (MFLU) herbarium. The ex-type living culture is deposited in the Mae Fah Luang Culture Collection (MFLUCC). Faces of fungi number (Jayasiri et al. 2015) and Index Fungorum number (www.indexfungorum.org) are provided. Samples were examined using a Nikon ECLIPSE 80i compound microscope and photographed with a Canon 600D digital camera fitted to the microscope. Measurements were made using Tarosoft (R) Image Frame Work programme and photo-plates were made by using Adobe Photoshop CS6 Extended version 10.0 software (Adobe Systems, United States).

\section{DNA extraction, PCR amplification and sequencing}

DNA was extracted from mycelium by using Biospin Fungus Genomic DNA Extraction Kit (BioFlux) (Hangzhou, P.R. China) and gene extraction kit (Bio Basic, Canada). PCR amplification was carried out using primers LROR/LR5 for the nuclear ribosomal large subunit 28S rDNA gene (LSU), NS1/NS4 for the nuclear ribosomal small subunit 18S rDNA gene (SSU) and ITS5/ITS4 for internal transcribed spacer rDNA region and covered 5.8S ribosomal part (ITS1, 5.8S rDNA and ITS2); partial fragments of the translation elongation factor 1-alpha (tefl) gene region was amplified using primers EF1-983F and EF1-2218R; and partial RNA polymerase subunit II ( $r p b 2$ ) was amplified with primers RPB2-5f and RPB2-7cr (Vilgalys \& Hester 1990, White et al. 1990, Carbone \& Kohn 1999, Sung et al. 2007). Primer sequences are available at the WASABI database at the AFTOL website (aftol.org). Amplification conditions followed Phukhamsakda et al. (2016). Purified PCR products were sequenced with primers mentioned above by Shanghai Sangon Biological Engineering Technology \& Services Co. (Shanghai, P.R. China).

\section{Sequence alignment and phylogenetic analyses}

The consensus sequences of the novel species were generated in Geneious (version 7.1.9 created by Biomatters, available from www.geneious.com). Similar sequences were retrieved using BLAST searches in GenBank (www.ncbi.nlm.nih.gov) and also from Ariyawansa et al. (2015), Phukhamsakda et al. (2016), Hyde et al. (2017), and these are listed in the accession table in Appendix 1. Sequences were aligned with MAFTT version 7.220 (Katoh \& Standley 2013) online sequence alignment tools (mafft.cbrc.jp/alignment/server), with minimal adjustments of the ambiguous nucleotides by visual examination and manually corrected in AliView programme (Larsson 2014). Leading or trailing gaps exceeding from primer binding site were trimmed from the alignments prior to tree building and alignment gaps were treated as missing data. The concatenation of the multigene alignment was created in MEGA 6 (Tamura et al. 2013).

A maximum likelihood analysis including 1,000 bootstrap replicates was performed at CIPRES using RAxML version 8.2.10 as part of the "RAxML-HPC2 on XSEDE" tool (Stamatakis 2006, Stamatakis et al. 2008, Miller et al. 2010). The general time reversible model (GTR) using proportions of invariable sites were applied with a discrete gamma distribution and four rate classes model were applied for nucleotide substitution. The best scoring tree was selected with a final likelihood value of -29062.646359. Maximum likelihood bootstrap support (MLBS) equal or greater than $70 \%$ are given near to each node (Fig. 1).

The majority rule consensus tree (MRC) from the Bayesian-inference analysis based on combined dataset of LSU, SSU, ITS, tef1, and $r p b 2$ sequence data was performed by using MrBayes on XSEDE version 3.2.6 (Ronquist et al. 2012). The model of evolution was inferred 
using jModeltest 2.1.7 (Guindon \& Gascuel 2003, Darriba et al. 2012). In our analysis, GTR+I+G model was used for each partition. The Bayesian inference posterior probabilities (PP) distribution (Zhaxybayeva \& Gogarten 2002) was estimated by Markov Chain Monte Carlo sampling (MCMC). Six simultaneous Markov chains were run for 1,000,000 generations and trees were sampled every $1000^{\text {th }}$ generation, thus 1,000 trees were obtained. The suitable burn-in phases were determined by traces inspected in Tracer version 1.6 (Rambaut et al. 2014). Based on the tracer analysis, the first 200 trees representing $20 \%$ of burn-in phase of the analyses were discarded while the remaining trees were used for calculating posterior probabilities in the majority rule consensus tree (critical value for the topological convergence diagnostic set to 0.01).

Phylogenetic trees and data files were visualized in FigTree v. 1.4 (Rambaut \& Drummond 2008). The phylogram with bootstrap values and/or posterior probabilities on the branches are presented in Fig. 1 by using graphical options available in Adobe Illustrator CS v. 6. All sequences generated in this study were submitted to GenBank (Appendix 1). The finalized alignment and tree were deposited in TreeBASE, submission ID: 24111 (http://www.treebase.org/). Maximum likelihood bootstrap values equal to or greater than $70 \%$ with Bayesian posterior probabilities (PP) equal or greater than 0.90 are presented below or above each node (Fig. 1).

\section{Results}

\section{Phylogenetic analyses}

The phylogeny based on a combined LSU, ITS, SSU, tef1, and rpb2 sequence data included 38 taxa representing Phaeoseptaceae and closely related families in Pleosporales. The dataset comprised a total of 4693 characters (965 characters for LSU, 617 characters for ITS, 1097 characters for SSU, 926 characters for tef1, 1061 characters for rpb2). Aigialus grandis (BCC 20000) and Neoastrosphaeriella krabiensis (MFLUCC 11-0025), from Aigialaceae, were used as the out group. The matrix has 2061 distinct alignment patterns, with 43.3\% undetermined characters or gaps. Estimated base frequencies were as follows: $\mathrm{A}=0.245073, \mathrm{C}=0.249429, \mathrm{G}=$ $0.276047, \mathrm{~T}=0.229452$; substitution rates $\mathrm{AC}=1.232711, \mathrm{AG}=2.440857, \mathrm{AT}=1.291268, \mathrm{CG}=$ $1.269789, \mathrm{CT}=6.315893, \mathrm{GT}=1.000000$; gamma distribution shape parameter $\alpha=0.766883$. A best scoring phylogram from maximum likelihood analysis showed similar topologies with the 50\% majority rule consensus tree (MRC) from Bayesian-inference analysis. A best scoring RAxML tree resulted with the value of likelihood: -29062.646359 (Fig. 1). Single gene phylogenetic analyses were also performed to compare tree topologies and clade stability with trees generated with the combined gene dataset. Phylogenies from individual genes were congruent with those obtained from the combined dataset (results not shown).

The new strain of Phaeoseptum clusters with the two other known species of Phaeoseptum (Fig. 1). The species is basal to P. aquaticum CBS 123113 and P. terricola MFLUCC 10-0102 and all three Phaeoseptum species constitute a strongly supported monophyletic clade (100\% in MLBT, $1.00 \mathrm{BSPP})$.

\section{Taxonomy}

Phaeoseptum mali Phukhams. \& K.D. Hyde, sp. nov.

Fig. 2

Index Fungorum number: IF556265; Facesoffungi number: FoF05982

Etymology - the epithet "mali" referring to host substrate, Malus halliana

Holotype - MFLU 19-0406

Saprobic on dead stems of Malus halliana Koehne. Sexual morph Ascomata 320-375 × 320 $360 \mu \mathrm{m}(\bar{x}=348 \times 327 \mu \mathrm{m}, \mathrm{n}=5)$, on surface of the host, visible as black spots or having a convex surface, sometime covered with a pseudoclypeus, immersed, solitary, scattered, globose, dark brown hyphae radiating outwards from the perdium wall, coriaceous, black to dark brown, roughwalled, papillate, with an apical ostiole. Ostiole central, dark brown to black, papillate, opened pore, ostiolate with periphyses. Peridium 5-19(-25 at apex) $\mu \mathrm{m}$ wide diam., multilayer, outer layer 


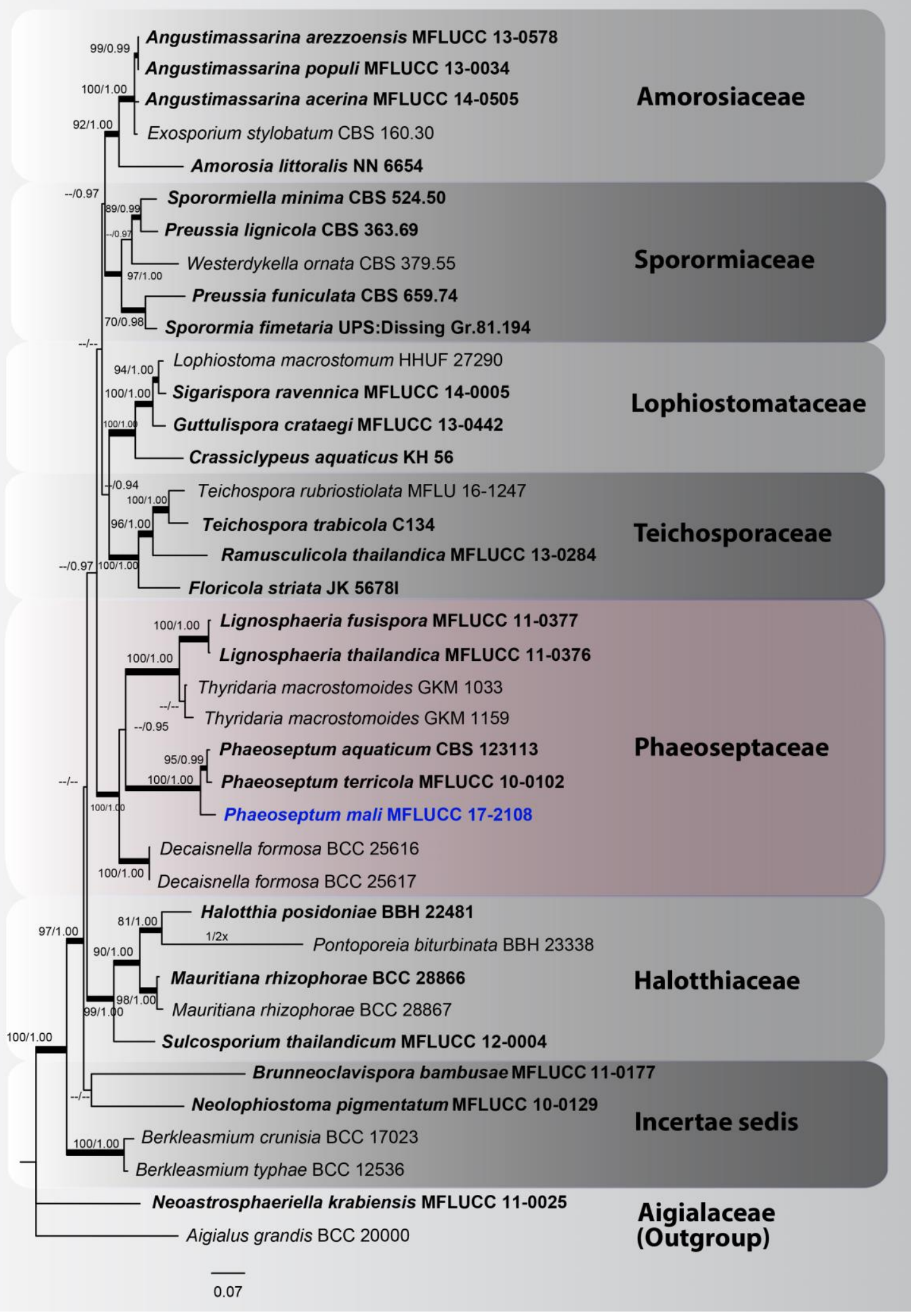

Fig. 1- Phylogram of 50\% majority rule consensus tree from the Bayesian-inference analysis based on combined dataset of LSU, ITS, SSU, tefl, and $r p b 2$ sequence data representing Phaeoseptaceae and closely related families in Pleosporales. The tree is rooted with Aigialus grandis (BCC 20000) and Neoastrosphaeriella krabiensis (MFLUCC 11-0025) in Aigialaceae (Pleosporales). Bootstrap support values for maximum likelihood analysis greater than $70 \%$ and clade credibility values greater than 0.90 (the rounding of values to 2 decimal proportions) from Bayesian-inference analysis are labelled below or above the nodes. Ex-type strains are in bold and black, the new isolate is indicated in blue. 

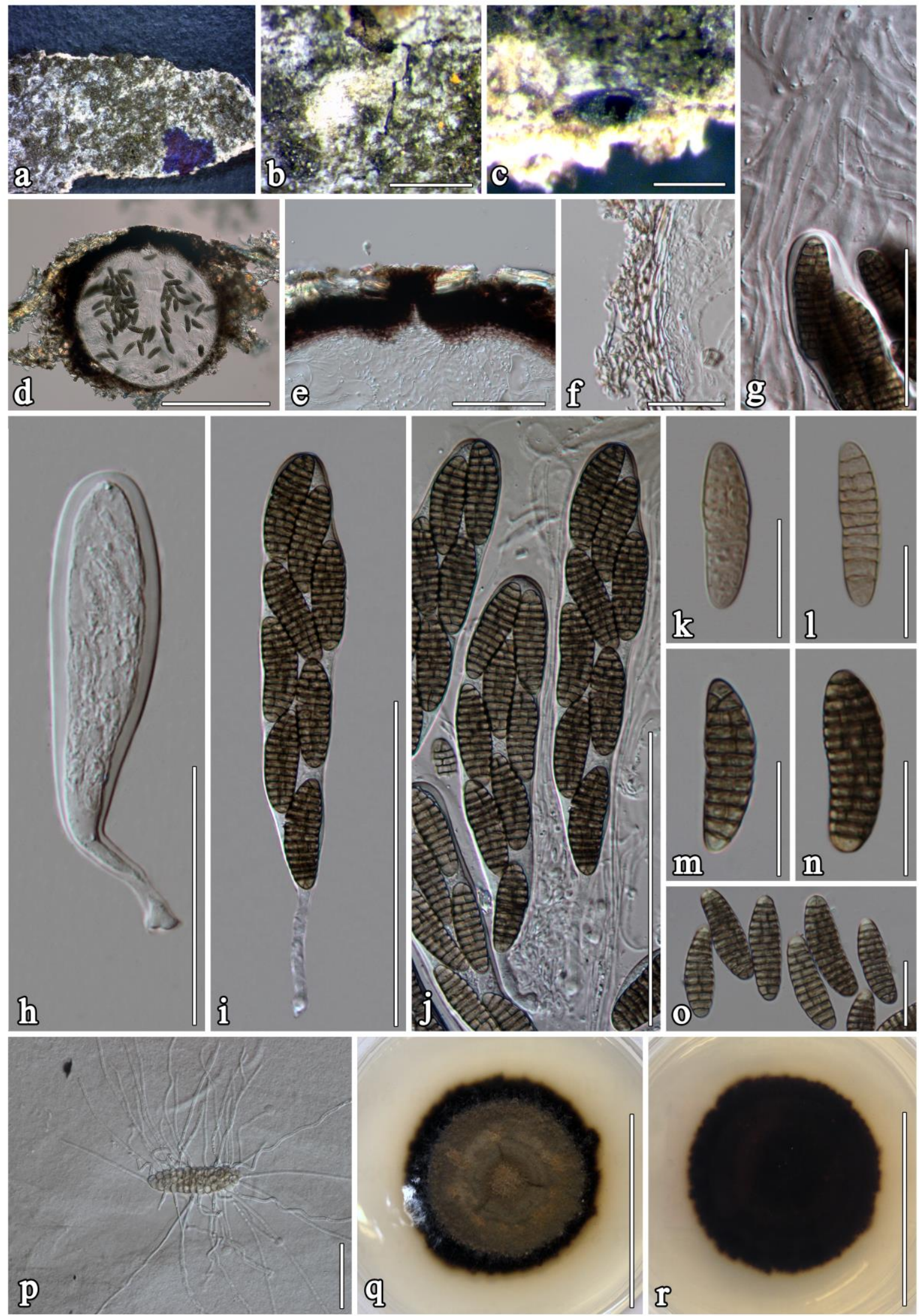

Fig. 2 - Phaeoseptum mali (MFLU 19-0406, holotype). a-c Appearance of ascomata on Malus halliana. d Vertical section through ascoma. e Ostiole canal. f Section of partial peridium layer. $\mathrm{g}$ Trabeculate pseudoparaphyses. $\mathrm{h}-\mathrm{j}$ Developmental stages of asci. $\mathrm{k}-\mathrm{O}$ Ascospores. $\mathrm{p}$ Germinated ascospore. $\mathrm{q}, \mathrm{r}$ Culture on MEA. Scale bars: $\mathrm{b}=500 \mu \mathrm{m}, \mathrm{c}, \mathrm{d}=200 \mu \mathrm{m}, \mathrm{e}, \mathrm{g}, \mathrm{h}=50 \mu \mathrm{m}, \mathrm{f}, \mathrm{k}-\mathrm{p}=$ $20 \mu \mathrm{m}, \mathrm{i}, \mathrm{j}=100 \mu \mathrm{m}, \mathrm{q}, \mathrm{r}=3 \mathrm{~cm}$. 
composed of 8-11 layers of dark brown to light brown, somewhat flattened cells of textura angularis, the inner layer comprising thin, hyaline cells. Hamathecium of dense, 0.9-1.7 $\mu \mathrm{m}$ wide $(\bar{x}=1.4 \mu \mathrm{m}, \mathrm{n}=50)$, filiform branches, anastomosing above asci, transverse septate, trabeculate pseudoparaphyses. Asci 85-190 × 19-32 $\mu \mathrm{m}(\bar{x}=140 \times 25 \mu \mathrm{m}, \mathrm{n}=30), 8$-spored, bitunicate, fisitunicate, cylindrical-clavate to elongate-clavate, apically rounded, ocular chamber clearly visible when immature. Ascospores $27-38 \times 8-13 \mu \mathrm{m}(\bar{x}=33 \times 10 \mu \mathrm{m}, \mathrm{n}=70)$, biseriate, muriform, allantoid, asymmetrical, partial overlapping, broad cylindrical, tapering towards the ends, round at both ends, with 11-14 transverse septa, and 1(-2) longitudinal septum in each cell, initially hyaline, becoming yellowish to brown at maturity, constricted at the median septum, cell above median septum slightly wider than below, rough-walled with verruculose surface, without mucilaginous sheath. Asexual morph Undetermined.

Culture characters - Colonies on MEA reaching $50 \mathrm{~mm}$ diam. after four weeks of incubation at $25{ }^{\circ} \mathrm{C}$, from above dark brown radiating outwards, wrinkled folded at the middle, dense, circulate in shape, flattened, umbonate, entire edge, fairly fluffy; reverse black at the middle and dark brown at the edges, orange pigment diffusing into the agar.

Material examined - China, Yunnan Province, Kunming city, in the botanical garden of Kunming Institute of Botany, on decay twigs of Malus halliana Koehne (Rosaceae), 21 March 2016, C. Phukhamsakda, CPCN09 (MFLU 19-0406, holotype), isotype in HKAS, ex-type living culture, MFLUCC 17-2108.

\section{Key to the species of Phaeoseptum}

1. Ascospores 19-25 $\times 5-7 \mu \mathrm{m}$, cylindrical, without a median septum ................. terricola

1. Ascospores with a median septum ...............................................

2. Ascospores 30-38 $\times 9-12 \mu \mathrm{m}$, broadly fusoid with rounded ends ................ aquaticum

2. Ascospores $27-38 \times 8-13 \mu \mathrm{m}$, broadly cylindrical with rounded ends ................... mali

\section{Discussion}

Malus halliana or hall crab apple is considered as a native tree of China and is widely distributed throughout Yunnan Province. Wild and cultivated M. halliana commonly occurs in shrubland forests and some basin areas (Zhang et al. 1993, Liu \& Tang 2004). It is also a major ornamental tree in Yunnan Province, where it grows in woodland garden with a dappled shade of sunlight (Rhodes \& Maxted 2016). At least 20 genera and 40 species of pleosporalean fungi have been recorded from Malus spp. (Farr \& Rossman 2019, Index Fungorum 2019) but interestingly only three fungi have been recorded on $M$. halliana; these are Alternaria brassicicola (Pleosporaceae), Magnibotryascoma mali (Teichosporacee) and Paucispora kunmingense (Lophiostomataceae) (Gu 2009, Hyde et al. 2017).

Species of Phaeoseptaceae live on woody substrates in various ecosystems. The family was introduced by Hyde et al. (2018), typified by Phaeoseptum with the type species P. aquaticum Zhang, J. Fourn. \& K.D. Hyde. Recent studies on the family have included Decaisnella (D. Formosa), Lignosphaeria (L. fusispora and L. thailandica), Neolophiostoma (N. pigmentatum), Phaeoseptum (P. aquaticum and P. terricola), and Thyridaria (T. macrostomoides( (Abdel-Wahab \& Jones 2003, Zhang et al. 2013, Ariyawansa et al. 2015, Thambugala et al. 2015, Phukhamsakda et al. 2016, Hyde et al. 2018). Initially, Phaeoseptum was reported to belong to the Halotthiaceae based on morphological characters and phylogenetic analysis of LSU sequence data (Zhang et al. 2013). With the discovery of more fungal taxa, the genus was later reported to constitute a monophyletic clade in Phaeoseptaceae (Hyde et al. 2018).

In this study, we introduce P. mali isolated from bark of fallen twigs of Malus halliana. The species is assigned to Phaeoseptum based on its unique morphological features such as globose and immersed ascomata, anastomosing pseudoparaphyses, cylindrical-clavate, pedicellate asci, allantoid and brown muriform ascospores. Phaeoseptum mali has ascomata $348 \times 327 \mu \mathrm{m}$ and asci $140 \times 25 \mu \mathrm{m}$, while $P$. terricola has ascomata $172 \times 184 \mu \mathrm{m}$ and asci $79 \times 16 \mu \mathrm{m}$ which are smaller in size than $P$. mali (Hyde et al. 2018). Based on morphology, $P$. mali is more similar to $P$. 
aquaticum, but the latter species has an ascomatal size of 300-400 $\times 400-600 \mu \mathrm{m}$ which is larger than P. mali (Zhang et al. 2013). In addition, P. aquaticum has been reported from submerged material from freshwater habitat while P. mali was collected from terrestrial habitats (Zhang et al. 2013). In a BLASTn search on NCBI GenBank, the closest matches to sequences of our isolate (MFLUCC 17-2108) is P. terricola strain MFLUCC 10-0102. The ITS sequence is $90 \%$ similar (11.6\% nucleotide differences in the ITS regions) while the $r p b 2$ sequence is $96 \%$ similar (4\% nucleotide differences in the $r p b 2$ regions). Phylogenetic trees obtained from Bayesian analysis and maximum likelihood analysis were similar in overall topology at the family level as previously reported (Ariyawansa et al. 2015, Phukhamsakda et al. 2016, Hyde et al. 2018), except for Neolophiostoma pigmentatum (MFLUCC 10-0129) and Brunneoclavispora bambusae (MFLUCC 11-0177), which are now classified as incertae sedis. Therefore, our new strain is introduced as a new species of Phaeoseptum based on guidelines proposed by Jeewon \& Hyde (2016).

Phylogeny recovered herein also indicates a different placement of Neolophiostoma pigmentatum Boonmee \& K.D. Hyde. Based on multigene phylogenetic analyses, N. pigmentatum was originally referred to the Halotthiaceae (Ariyawansa et al. 2015, Wijayawardene et al. 2018), while, Hyde et al. (2018) transferred it to Phaeoseptaceae. In our phylogeny, N. pigmentatum formed a lineage separated from both Halotthiaceae and Phaeoseptaceae. This topological difference may be because of a highly variable gene region such as ITS which was analysed with increased taxon sampling. Another peculiar phylogenetic finding in this study is the placement of Thyridaria macrostomoides, which is similar to Lignosphaeria in having phragmosporous, elongate, cylindrical to fusiform and hyaline ascospores. However, the type specimen of Thyridaria (T. broussonetiae (Sacc.) Traverso) is in a distinct lineage in Thyridariaceae (Jaklitsch \& Voglmayr 2016). To clarify the familial placement, the material needs to be re-examined (Abdel-Wahab \& Jones 2003, Mugambi \& Huhndorf 2009).

\section{Acknowledgements}

The authors would like to thank the Royal Golden Jubilee PhD Program under Thailand Research Fund (RGJ) for a personal grant to C. Phukhamsakda (Scholarship no. PHD/0020/2557 to study towards a PhD). Dr. Shaun Pennycook kindly checked and suggested Latin name for the new taxon. R. Jeewon thanks University of Mauritius for research support.

\section{References}

Abdel-Wahab MA, Jones EB. 2003 - Decaisnella formosa sp. nov. (Ascomycota, Massariaceae) from an Australian sandy beach. Canadian Journal of Botany 81, 598-600.

Ariyawansa HA, Hyde KD, Jayasiri SC, Buyck B et al. 2015 - Fungal diversity notes 111-252 Taxonomic and phylogenetic contributions to fungal taxa. Fungal Diversity 75, 27-274.

Carbone I, Kohn LM. 1999 - A method for designing primer sets for speciation studies in filamentous ascomycetes. Mycologia 91, 553-556.

Chomnunti P, Hongsanan S, Aguirre-Hudson B, Tian Q et al. 2014 - The sooty moulds. Fungal Diversity 66, 1-36.

Darriba D, Taboada GL, Doallo R, Posada D. 2012 - jModelTest 2: more models, new heuristics and parallel computing. Nature Methods 9, 772.

Farr DF, Rossman AY. 2019 - Fungal databases, Systematic mycology and microbiology laboratory, ARS, USDA, Retrieved January 10, 2019, from http://nt.arsgrin.gov/fungaldatabases.

Gu W. 2009 - Bioactive metabolites from Alternaria brassicicola ML-P08, an endophytic fungus residing in Malus halliana. World Journal of Microbiology and Biotechnology 25, 16771683.

Guindon S, Gascuel O. 2003 - A Simple, Fast, and Accurate Algorithm to Estimate Large Phylogenies by Maximum Likelihood. Systematic Biology, 52, 696-704. 
Hyde KD, Chaiwan N, Norphanphoun C, Boonmee S et al. 2018 - Mycosphere notes: 169-224. Mycosphere 9, 271-430.

Hyde KD, Norphanphoun C, Abreu VP, Bazzicalupo A et al. 2017 - Fungal diversity notes 603708: taxonomic and phylogenetic notes on genera and species. Fungal Diversity 87, 1-235.

Index Fungorum. 2019 - Available from: http://www.indexfungorum.org/Names/Names.asp. (accessed February 2019).

Jaklitsch WM, Voglmayr H. 2016 - Hidden diversity in Thyridaria and a new circumscription of the Thyridariaceae. Studies in Mycology 85, 35-64.

Jayasiri SC, Hyde KD, Ariyawansa HA, Bhat J et al. 2015 - The Faces of Fungi database: fungal names linked with morphology, phylogeny and human impacts. Fungal Diversity 74, 3-18.

Jeewon R, Hyde KD. 2016 - Establishing species boundaries and new taxa among fungi: recommendations to resolve taxonomic ambiguities. Mycosphere 7: 1669-1677.

Katoh K, Standley K. 2013 - MAFFT multiple sequence alignment software version 7: improvements in performance and usability. Molecular Biology and Evolution 30, 772-780.

Kodsueb R, Vijaykrishna D, Aptroot A, Lumyong S et al. 2006 - The family Pleosporaceae: intergeneric relationships and phylogenetic perspectives based on sequence analyses of partial 28S rDNA. Mycologia 98, 571-583.

Larsson A. 2014 - AliView: a fast and lightweight alignment viewer and editor for large data sets. Bioinformatics 30, 3276-3278.

Liu AR, Chen SC, Wu SY, Xu T et al. 2010 - Cultural studies coupled with DNA based sequence analyses and its implication on pigmentation as a phylogenetic marker in Pestalotiopsis taxonomy. Molecular Phylogenetics and Evolution 57, 528-535.

Liu JK, Hyde KD, Jeewon R, Phillips AJL et al. 2017 - Ranking higher taxa using divergence times: a case study in Dothideomycetes. Fungal Diversity 84, 75-99.

Liu Z, Tang G. 2004 - A study on cultivar classification system of Malus halliana Koehne. Journal of Nanjing Forestry University 28, 101-106.

Miller MA, Pfeiffer W, Schwartz T. 2010 - Creating the CIPRES Science Gateway for inference of large phylogenetic trees. In Gateway Computing Environments Workshop 2010 (GCE), New Orleans, Louisiana, November 2010, pp 1-8.

Mugambi GK, Huhndorf SM. 2009 - Molecular phylogenetics of Pleosporales: Melanommataceae and Lophiostomataceae re-circumscribed (Pleosporomycetidae, Dothideomycetes, Ascomycota). Studies in Mycology 64, 103-121.

Phukhamsakda C, Ariyawansa HA, Phillips AJ, Wanasinghe DN et al. 2016 - Additions to Sporormiaceae: introducing two novel genera, Sparticola and Forliomyces, from Spartium. Cryptogamie Mycologie 37, 75-98.

Pinnoi A, Jeewon R, Sakayaroj J, Hyde KD et al. 2007 - Berkleasmium crunisia sp. nov. and its teleomorphic affinities to the Pleosporales based on 18S, 28S and ITS-5.8S rDNA sequence analyses. Mycologia 99, 378-384.

Rambaut A, Drummond A. 2008 - FigTree: tree figure drawing tool, version 122 Institute of Evolutionary Biology, University of Edinburgh.

Rambaut A, Suchard MA, Xie D, Drummond AJ. 2014 - Tracer v16, available from http://beast.bio.ed.ac.uk/Tracer.

Rhodes L, Maxted N. 2016 - Malus halliana. The IUCN Red List of Threatened Species Downloaded on 5 March 2019.

Ronquist F, Teslenko M, Van Der Mark P, Ayres DL et al. 2012 - MrBayes 3.2: efficient Bayesian phylogenetic inference and model choice across a large model space. Systematic Biology 61, 539-542.

Stamatakis A, Hoover P, Rougemont J. 2008 - A rapid bootstrap algorithm for the RAxML web servers. Systematic Biology 57, 758-771.

Stamatakis A. 2006 - RAXML-VI-HPC: maximum likelihood-based phylogenetic analyses with thousands of taxa and mixed models. Bioinformatics 22, 2688-2690. 
Sung GH, Sung JM, Hywel-Jones NL, Spatafora JW. 2007 - A multi-gene phylogeny of clavicipitaceae (ascomycota, fungi): Identification of localized incongruence using a combinational bootstrap approach. Mol Phylogenet Evol 44: 1204-1223.

Tamura K, Stecher G, Peterson D, Filipski A, Kumar S. 2013 - MEGA6: molecular evolutionary genetics analysis version 6.0. Molecular Biology and Evolution 30, 2725-2729.

Thambugala KM, Hyde KD, Tanaka K, Tian Q et al. 2015 - Towards a natural classification and backbone tree for Lophiostomataceae, Floricolaceae, and Amorosiaceae fam. nov. Fungal Diversity 74, 199-266.

Vilgalys R, Hester M. 1990 - Rapid genetic identification and mapping of enzymatically amplified ribosomal DNA from several Cryptococcus species. Journal of Bacteriology 172, 4238-4246.

Wanasinghe DN, Jeewon R, Jones EBG, Boonmee S et al. 2018 - Novel palmicolous taxa within Pleosporales: multigene phylogeny and taxonomic circumscription. Mycological Progress 17, 571-590.

Wanasinghe DN, Jeewon R, Jones EBG, Tibpromma S et al. 2017a - Saprobic Dothideomycetes in Thailand: Muritestudina gen. et sp. nov. (Testudinaceae) a new terrestrial pleosporalean ascomycete, with hyaline and muriform ascospores. Studies in Fungi 2, 219-234.

Wanasinghe DN, Phookamsak R, Jeewon R, Hyde KD et al. 2017b - A family level rDNA based phylogeny of Cucurbitariaceae and Fenestellaceae with descriptions of new Fenestella species and Neocucurbitaria gen. nov. Mycosphere 8, 397-414.

White TJ, Bruns T, Lee SJ, Taylor JW. 1990 - Amplification and direct sequencing of fungal ribosomal RNA genes for phylogenetics. PCR protocols: a guide to methods and applications $18,315-322$.

Wijayawardene NN, Hyde KD, Lumbsch HT, Liu JK et al. 2018 - Outline of Ascomycota: 2017. Fungal Diversity 88, 167-263.

Wijayawardene NN, Hyde KD, Rajeshkumar KC, Hawksworth DL et al. 2017 - Notes for genera: Ascomycota. Fungal diversity 86, 1-594.

Zhang W, Zhang J, Hu X. 1993 - Distribution and diversity of Malus germplasm resources in Yunnan, China. HortScience 28, 978-980.

Zhang Y, Fournier J, Phookamsak R, Bahkali AH et al. 2013 - Halotthiaceae fam. nov. (Pleosporales) accommodates the new genus Phaeoseptum and several other aquatic genera. Mycologia 105, 603-609.

Zhang Y, Jeewon R, Fournier J \& Hyde KD. 2008 - Multi-gene phylogeny and morphotaxonomy of Amniculicola lignicola: novel freshwater fungus from France and its relationships to the Pleosporales. Fungal Biology 112, 1186-1194.

Zhang Y, Wang HK, Fournier J, Crous PW et al. 2009 - Towards a phylogenetic clarification of Lophiostoma/Massarina and morphologically similar genera in the Pleosporaceae. Fungal Diversity 38, 225-251.

Zhaxybayeva O, Gogarten JP. 2002 - Bootstrap, Bayesian probability and maximum likelihood mapping: exploring new tools for comparative genome analyses. BMC Genomics 3: 4. 
Appendix 1 GenBank accession numbers used in this study. GenBank accessions marked in bold represent new sequences generated in the current study.

\begin{tabular}{|c|c|c|c|c|c|c|}
\hline \multirow{2}{*}{ Taxon } & \multirow{2}{*}{ Culture collection } & \multicolumn{5}{|c|}{ GenBank accession numbers } \\
\hline & & LSU & SSU & ITS & tef1 & $r p b 2$ \\
\hline Aigialus grandis & BCC 20000 & GU479775 & GU479739 & - & GU479839 & GU479814 \\
\hline morosia littoralis & NN 6654 & AM292055 & AM292056 & AM292047 & - & - \\
\hline Angustimassarina acerina & MFLUCC 14-0505 & KP888637 & NG_063573 & NR_138406 & KR075168 & - \\
\hline Angustimassarina arezzoensis & MFLUCC $13-0578$ & KY496722 & KY501113 & KY496743 & KY514392 & - \\
\hline Angustimassarina populi & MFLUCC 13-0034 & KP888642 & KP899128 & KP899137 & KR075164 & - \\
\hline Berkleasmium crunisia & BCC 17023 & DQ280271 & - & DQ280265 & - & - \\
\hline Berkleasmium typhae & BCC 12436 & DQ280275 & - & DQ28026 & - & - \\
\hline Brunneoclavispora bambusae & MFLUCC 11-0177 & KT426562 & MG520999 & NR_156401 & - & - \\
\hline Crassiclypeus aquaticus & CBS 143639 & LC312526 & LC312468 & LC312497 & LC312555 & LC312584 \\
\hline Decaisnella formosa & BCC 25617 & GQ925847 & GQ925834 & - & GU479850 & GU479824 \\
\hline Decaisnella formosa & BCC 25616 & GQ925846 & GQ925833 & - & GU479851 & GU479825 \\
\hline Exosporium stylobatum & CBS 16030 & JQ044447 & - & JQ044428 & - & - \\
\hline Floricola striata & JK 5678I & GU301813 & GU296149 & - & GU479852 & GU371758 \\
\hline Guttulispora crataegi & MFLUCC 13-0442 & NG_059563 & KP899125 & NR_154070 & KR075161 & - \\
\hline Halotthia posidoniae & BBH 22481 & GŪ479786 & GU479752 & - & - & - \\
\hline Lignosphaeria fusispora & MFLUCC 11-0377 & KP888646 & - & KP899140 & - & - \\
\hline Lignosphaeria thailandica & MFLUCC $11-0376$ & KP888645 & - & KP899139 & - & - \\
\hline Lophiostoma macrostomum & HHUF 27290 & AB433273 & AB521731 & AB433275 & LC001752 & - \\
\hline Mauritiana rhizophorae & BCC 28867 & GU371825 & GU371833 & - & GU371818 & GU371797 \\
\hline Mauritiana rhizophorae & BCC 28866 & GU371824 & GU371832 & - & GU371817 & GU371796 \\
\hline Neoastrosphaeriella krabiensis & MFLUCC 11-0025 & JN846729 & JN846739 & NR_120004 & - & - \\
\hline Neolophiostoma pigmentatum & MFLUCC 10-0129 & KT324588 & KT324589 & KT324587 & KT324590 & - \\
\hline Phaeoseptum aquaticum & CBS 123113 & JN644072 & - & KY940803 & - & - \\
\hline Phaeoseptum mali & MFLUCC 17-2108 & МK625197 & MK625211 & MK659580 & MK647990 & MK647991 \\
\hline Phaeoseptum terricola & MFLUCC 10-0102 & MH105779 & MH105780 & MH105778 & MH105781 & MH105782 \\
\hline Pontoporeia biturbinata & BBH 23338 & GU479796 & GU479763 & - & - & GU479837 \\
\hline Preussia lignicola & CBS 363.69 & DQ384098 & - & GQ203783 & - & - \\
\hline Preussia funiculata & CBS 65974 & GU301864 & GU296187 & - & GU349032 & GU371799 \\
\hline Ramusculicola thailandica & MFLUCC 13-0284 & KP888647 & KP899131 & KP899141 & KR075167 & - \\
\hline Sigarispora ravennica & MFLUCC 14-0005 & KP698414 & KP698415 & KP698413 & - & - \\
\hline Sporormia fimetaria & UPS:Dissing Gr.81.194 & GQ203729 & - & GQ203769 & - & - \\
\hline
\end{tabular}


Appendix 1 Continued.

\begin{tabular}{llccccc}
\hline \multirow{2}{*}{ Taxon } & \multirow{2}{*}{ Culture collection } & \multicolumn{5}{c}{ GenBank accession numbers } \\
\cline { 3 - 7 } & & LSU & SSU & ITS & tef1 & rpb2 \\
\hline Sporormiella minima & CBS 524.50 & MH868263 & - & MH856741 & - & - \\
Sulcosporium thailandica & MFLUCC 12-0004 & KT426563 & KT426564 & MG520958 & - & - \\
Teichospora rubriostiolata & MFLU 16-1247 & MG829086 & MG829186 & MG828974 & KU601609 & KU601599 \\
Teichospora trabicola & C134 & KU601591 & - & KU601591 & KU601601 & KU601600 \\
Thyridaria macrostomoides & GKM 1033 & GU385190 & - & - & GU327776 & - \\
Thyridaria macrostomoides & GKM 1159 & GU385185 & - & - & GU327778 & - \\
Westerdykella ornata & CBS 379.55 & NG_057861 & GU296208 & NR_103587 & GU349021 & GU371803 \\
\hline
\end{tabular}

